\title{
Geomatics in Injury Prevention: The Science, the Potential and the Limitations
}

\section{Michael D. Cusimano}

University of Toronto

\section{Mary Chipman}

University of Toronto

\section{Richard H. Glazier}

University of Toronto

\section{Claus Rinner}

University of Toronto

\section{Sean P. Marshall}

St. Michael's Hospital

\section{digital.library.ryerson.ca/object/388}

\section{Please Cite:}

Cusimano, M. D., Chipman, M., Glazier, R. H., Rinner, C., \& Marshall, S. P. (2007). Geomatics in injury prevention: The science, the potential and the limitations. Injury Prevention, 13, 51-56.

doi:10.1136/ip.2006.012468

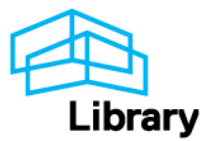


METHODOLOGIC ISSUES

\title{
Geomatics in injury prevention: the science, the potential and the limitations
}

\author{
M D Cusimano, M Chipman, R H Glazier, C Rinner, S P Marshall
}

Injury Prevention 2007;13:51-56. doi: 10.1136/ip.2006.012468

See end of article for authors' affiliations

Correspondence to Dr M D Cusimano, Injury

Prevention Research Office, St Michael's Hospital, 38 Shuter Street, Suite 2-006, Toronto, Ontario, Canada M5B 1A6; injuryprevention@smh. toronto.on.ca

Accepted 3 August 2006

\begin{abstract}
Background: Geomatics describes the activities involved in acquiring and managing geographical data and producing geographical information for scientific, administrative and technical endeavors. As an emerging science, geomatics has a great potential to support public health. Geomatics provides a conceptual foundation for the development of geographic information systems (GIS), computerized tools that manage and display geographical data for analytical applications. As descriptive epidemiology typically involves the examination of person, place and time in the occurrence of disease or injury, geomatics and GIS can play an important role in understanding and preventing injury.

Aim: This article provides a background to geomatics for those in the injury prevention field who are unfamiliar with spatial analysis. We hope to stimulate researchers and practitioners to begin to use geomatics to assist in the prevention of injury.

Methods: The authors illustrate the potential benefits and limitations of geomatics in injury prevention in a non-technical way through the use of maps and analysis.

Results: By analysing the location of patients treated for fall injuries in Central Toronto using GIS, some demographic and land use variables, such as household income, age, and the location of homeless shelters, were identified as explanatory factors for the spatial distribution.

Conclusion: By supporting novel approaches to injury prevention, geomatics has a great potential for efforts to combat the burden of injury. Despite some limitations, those with an interest in injury prevention could benefit from this science.
\end{abstract}

$\mathrm{D}$ escriptive epidemiology typically involves the examination of person, place and time in the occurrence of disease or injury. Geomatics is an emerging science with great potential to expand our understanding of all these factors. Geomatics is the science of acquiring, integrating, managing, analyzing, visualizing and disseminating geospatially referenced information to support decision making across an increasing variety of applications. ${ }^{1}$ Geographic information systems (GIS) is a tool in geomatics used for the geographical analysis that is crucial to better understand injury.

This article provides an overview of geomatics and GIS and its use in public health, particularly in the specialty of injury prevention, with some examples. By outlining the benefits and limitations of geomatics in a non-technical way, we hope to stimulate researchers and practitioners to begin to use geomatics to assist in the prevention of injury.

\section{CORE GEOMATICS CONCEPTS}

Geomatics is an emerging science with associated applied technologies focused on the geospatial dimension of features, activities and processes, and requires quantitative and analytical methods and approaches. Geomatics has provided enabling technologies in a wide range of sciences including the social sciences, engineering and land use planning, and is gaining popularity in disciplines such as public health. In the specialty of injury prevention in particular, there are considerable benefits that can be exploited, yet this potential waits to be fully realized.

Geomatics is the larger area of inquiry which contains GIS. A GIS provides a method of linking social, economic, ecological and demographic factors with individual-level data aggregated at a variety of geographical scales. The most common use of GIS is to create maps for display and analytical usage. GIS provides a powerful tool to stakeholders interested in injury prevention, through its ability to display geographical information and to combine multiple databases to identify specific patterns and determinants.

Essentially, GIS refers to "an organized collection of computer hardware, software, geographically organised data and personnel designed to efficiently capture, store, update, manipulate, analyse and display all forms of geographically referenced information". ${ }^{2}$ A typical, geo-relational GIS database comprises two types of information: geometric data (eg, points and topics representing street addresses, postal codes, cities, political regions and countries, or coordinates of longitude and latitude) and attribute data (including socioeconomic data, such as census data, and data relevant to the occurrence or prevention of injury, such as the characteristics of patients visiting emergency departments for brain injuries).

Some of the most common applications of geomatics include commercial and industrial site planning and market analysis, land use and environmental planning, the provision of social services, logistics and optimization of emergency service response time. ${ }^{3}$ The ability of GIS to analyze geographical phenomena and predict spatial patterns can be applied as much in forecasting of retail store sales as in determining neighborhoods with a high risk of injury. Therefore, public health and injury prevention draws from many of the principles used in these applications.

Although geomatics is often associated with the visual mapping of data, this is one small feature of the approach. Geomatics methods subsumed in GIS are characterized by three essential and inter-related functions: (1) the organization of geographically referenced data in databases; (2) the visualization of data on maps and graphs; and (3) the spatial analysis of data. $^{4-6}$

Abbreviation: GIS, geographic information systems 
As the data in a geographical database are related through spatial relations, GIS has the power to facilitate the convergence of multisectoral data. ${ }^{4}$ GIS can potentially bring together databases from multiple sectors such as health, housing, police, urban planning and transportation, while simplifying the sharing and exploration of multiple, complex data-sets through data visualization technology. Spatial data are particularly powerful because they can be displayed in graphs, charts and, most significantly, maps. Currently, the automated generation of maps is the most widespread application of GIS in the healthcare research sector. ${ }^{27}$

Through their spatial analysis capabilities, geomatics applications allow researchers to analyze and depict health data in new, highly effective ways, including animated maps showing a pattern or injury or disease over time, or density maps, which allow for the visualization of spatial clusters. Exploratory analysis and model building are two especially powerful types of spatial analysis in GIS applications. Exploratory analysis allows the analyst to sift meaningfully through spatial data, identify unusual spatial patterns and formulate hypotheses to guide scientific investigation. ${ }^{8} 9$ Model building includes procedures for testing hypotheses about the etiology of diseases and injury. ${ }^{4}$

The ability to map health data, identify and formulate hypotheses about spatial patterns, and build models makes GIS a powerful tool for public health, health policy research and epidemiology. These techniques are effective when the variables of diseases or health concerns studied are spatially distributed or are inter-related with other variables with similar or related geographical patterns. In their simplest forms, these analyses show spatial relationships between variables that are helpful and policy-relevant. Geomatics can analyze important health issues at international, national and local levels, and has the potential to determine the geographical distribution and variation of disease (prevalence and incidence), map populations at risk, stratify risk factors, assess resource allocation (health services and schools), as well as plan and target interventions, and monitor diseases and interventions over time. ${ }^{2}$ GIS tools can also assist in planning optimal locations for healthcare and related facilities, and in mapping or locating intervention or health promotion programs that will have maximal effect on the community.

\section{USE OF GEOMATICS IN PUBLIC HEALTH}

Although the use of maps in public health dates back to the 18th century, it is only recently that technology has facilitated the documentation of population health in spatial databases. ${ }^{5}{ }^{10}$ An early example in disease mapping is John Snow's use of a London neighborhood map during his investigation of a cholera outbreak in $1860 .{ }^{11}$ By indicating on this map where cholera deaths had occurred, Snow was able to deduce from their spatial clustering that the Broad Street water pump may have contributed to the outbreak long before the etiology of cholera was discovered. ${ }^{4}$ In health geography, computer mapping was first applied as a display tool during the 1960s. However, only in the past 15 years has the rapidly growing performance of personal computers enabled researchers to use desktop GIS software to examine health data spatially and produce maps on their own. ${ }^{5}$ Although the use of GIS in geographical research is well established, full implementation of its approaches in health is a relatively new phenomenon. Recently GIS has been used in the identification of lead hazards and children at risk in a neighborhood, in the surveillance and monitoring of sexuallytransmitted diseases, in environmental health, in the analysis of disease policy and planning, and in access to health services. ${ }^{5}{ }^{10}{ }^{12-17}$
In Ontario, Canada, GIS was used to map reports and present data outlining health outcomes and possible relationships with the environmental use of Great Lakes basins in a policy-friendly format. ${ }^{18}$ Another study used GIS to develop preventive measures for bicycle travel on sidewalks, roads and off-road paths in two major cities in Ontario. ${ }^{19}{ }^{20}$ Further, the utility of a GIS approach was explored in Southeast Toronto: GIS was used to integrate a wide range of routinely collected information relevant to the determinants and manifestations of respiratory health. ${ }^{21}{ }^{22}$ GIS was also used to examine geospatial clustering for disparities in mammography use in Toronto. ${ }^{23}$

Some public health departments are beginning to use GIS to monitor and plan service delivery. For example, the Florida state-wide web-based GIS application is being used by local health agencies to help evaluate and redirect health programs and services, using health and demographic data at the census tract level. As interest and participation in the program has increased, the amount of data available to the stakeholders has improved, along with the financial, technical and staffing resources devoted to the project. ${ }^{24}$

Crime analysis and traffic enforcement is a specialty in which geomatics is increasingly used, where injury prevention is relevant. The use of GIS by law enforcement agencies has assisted in their efforts to better understand the geographical patterns of crime and traffic collisions and to better allocate police resources. Police can use GIS to map crime locations to identify crime hotspots so as to focus police resources and socioeconomic data in preventive efforts such as public awareness campaign and community policing strategies. ${ }^{25}$ Data on crime, such as homicides, are often readily available to the general public - for example, a casual user can navigate through simple web-based maps to visualize the locations of homicides, such as one that the Toronto Star has developed for the Greater Toronto Area. ${ }^{26}$

Researchers with an interest in analysis of violent crime have used GIS to examine the relationship between the number of assaults and the density of liquor stores and establishments serving alcohol at the ZIP code area level, including socioeconomic variables as indicators of social deprivation. ${ }^{27}$ Rates of assaults were related to social indicators such as poverty and proportion of visible minorities, as well as the density of liquor stores and drinking establishments in poor and rural areas, but in wealthier neighborhoods, the density of drinking establishments had little effect on assault rates.

\section{INJURY PREVENTION AND CONTROL: AN EXAMPLE OF THE POTENTIAL OF GEOMATICS IN PUBLIC HEALTH}

Study of injuries is a subject that could benefit tremendously from a geomatics approach. Over five million people worldwide die from injuries each year. Injuries are responsible for more deaths than HIV/AIDS and malaria combined. Globally, the leading causes of injury are traffic collisions, followed by falls, homicide and assault and self-inflicted injuries. ${ }^{28}$ In the US, unintentional injury is the fifth leading cause of death, and the leading cause of death for those $<45$ years. ${ }^{29}$

Understanding the where, when, who and how of injury is essential in developing strategies for all phases of prevention and control. The geocoding of the locations of injury occurrence, and the residence of the injury victim contributes to our understanding of environmental and individual factors related to injury. Geocoding translates the addresses associated with injury events or injured persons to geographic coordinates, allowing for the integration with existing spatial data such as those from the Census. Demographic data are particularly useful to develop risk profiles and explain unusual injury counts with various socioeconomic data. This approach has 
shortcomings in mapping long-term exposure factors for disease, where exposure to environmental hazards, such as carcinogens, can develop over years. ${ }^{30}$ However, the sudden nature of injury makes this approach well suited to injury prevention research.

Population health determinants such as income and social status, education, employment or working conditions, social and physical environments, personal health practices, healthy child development, biological and genetic endowment, health services, sex and culture are believed to have a relationship with injury patterns. ${ }^{31}{ }^{32}$ Although each of these factors alone plays an important part in injury in general, the complex interrelation of factors may have a different role in specific geographical locations and community extents. Geomatics has the potential of being applied to understanding injury and its prevention and control in most jurisdictions internationally through ecological studies, as most countries routinely collect such demographic data through periodic census of their populations.

There are a few examples for the use of GIS in the injury field. GIS was used to strategically plan the locational patterns for a proposed trauma center network in the UK and to outline their catchment areas. ${ }^{33}$ GIS has also been used to predict pedestrian injuries and to develop traffic accident information systems to assess risks of different types of traffic collisions. ${ }^{34-37}$ An injury-surveillance GIS for San Diego County was developed from a combination of several existing data sources that showed the cause-and-effect relationship between different types of traffic crashes and fostered several community-based programs. $^{38}$

GIS has also been used to study patterns of intentional injuries. The results of studies of the relationship of assaults and abuse with geographical location, and the frequency and type of drug use in Baltimore had strong implications for the location of drug-prevention and other HIV-prevention activities. ${ }^{39-42}$ Many researchers have emphasized the importance of examining the social context of health-related behaviors, and identifying geographical areas and population groups at high risk of injury. ${ }^{37} 43$

\section{EXAMPLE OF A GEOMATICS APPROACH TO INJURY PREVENTION}

The Institute for Clinical Evaluative Sciences has developed a series of atlases covering the province of Ontario on disease and health services, including an atlas entitled Injuries in Ontario. ${ }^{44}$ This is one example of using GIS as a descriptive tool that maps injuries at the county level for the province of Ontario. The maps show some distinct differences between rural and urban areas, as well as between southern and northern regions. Our own work goes beyond this and uses a geomatics framework to analyze and predict injury patterns and work with stakeholders to use data effectively.

The following maps illustrate a small sample from our own work. Fig 1 illustrates the density of the locations of injuries related to falls for the population aged $\geqslant 65$ years in Central Toronto in 2004. Fig 2 illustrates the density of fall injuries for the adult population aged 19-64 years. These data are from Toronto Emergency Medical Services and represent ambulance dispatch locations.

Figs 3-5 illustrate the use of socioeconomic and environmental data in an ecological study to explain the spatial distribution of injuries and for model building and evaluation. Fig 3 shows the density of persons aged $>65$ years using a dotdensity map to help explain the pattern in map l. Fig 4 shows the mean household income and map 5 (fig 5) the location of homeless shelters.
To create a map showing the incidence of injury, the hospital database, which includes the address for each patient, was geocoded. This geocoded database was then imported into ArcGIS, one of two major GIS software packages. ArcGIS has the capability to create density maps like those shown in maps 1 and 2 . The kernel density function calculates the density of points (each representing the patient's address) and is very useful as a visualization technique, as it removes the issue of overlapping points. ${ }^{25}$ This is an advantage in the specialty of injury prevention as it discusses the issue of data privacy by not showing actual locations. Several areas with an unusually high density of fall-related trauma cases are apparent, the largest such hotspot located in the east end of Toronto's downtown core.

For falls in the population aged $\geqslant 65$ years, the pattern is much more spread out than the distribution of falls in the population aged 19-65 years, where there is only one major concentration of fall injuries, in the eastern downtown core. Maps 4 and 5 show this area as having a low mean household income and a high concentration of homeless shelters. Also, people living in low-income areas are shown to be at the highest risk of injury, so this finding is not coincidental. ${ }^{27}{ }^{44}$ Other demographic, environmental or social variables could also be similarly mapped to help explain the spatial patterns of the outcome variable (eg, fall injuries).

\section{KNOWLEDGE TRANSLATION AND GIS}

In addition to the development of health, disease or injury risk profiles by public health researchers, recent developments in GIS and the world wide web have enabled the use of web-based mapping, which allows a broad audience to access health determinant datasets. These can be centrally updated, thus resolving issues of data currency. Also, because regional agencies are working with a shared dataset, consistency in policy development and program planning is also encouraged. ${ }^{45}$ Hence, GIS has the potential to be a catalyst for interdisciplinary and organizational collaboration, providing for regional or national coordination and the ultimate mobilization of injury prevention and control knowledge in communities where it is needed. ${ }^{46}$ The formation of data partnerships and data sharing are encouraged at the community level, owing to the ability of practitioners, planners and researchers to organize and integrate datasets spatially into a coherent whole. ${ }^{47-49}$

The successful uptake of web-based GIS applications is largely dependent on the implementation of effective, accompanying knowledge translation processes. ${ }^{50}$ Identified barriers to the use of GIS include differences in organizational priorities, computer skills and facilities, and spatial data-handling skills; awareness of and motivation to use injury surveillance data; and organizational characteristics such as turnover, internal restructuring and organizational resources. Needs assessments conducted by the Canadian Network of Centers of Excellence in Geomatics (GEOIDE) found that knowledge of what data exist and locating these data is a major problem for health professionals. ${ }^{51}$ Information about the datasets, interpretation and provisos for use must be targeted to increase the understanding of professional and non-professional service users. ${ }^{44}$

Knowledge translation strategies may also be critical for determining the level of operational use of GIS information by targeted audiences. How GIS is used and whether for descriptive purposes, analytical functions such as resource targeting or strategic tasks may have high variability among different communities of users. ${ }^{49}$ Training program working with GIS datasets must target skill development so that users can understand the essential characteristics of key datasets and the way they might be used in policy decision making and program planning. ${ }^{52}$ 

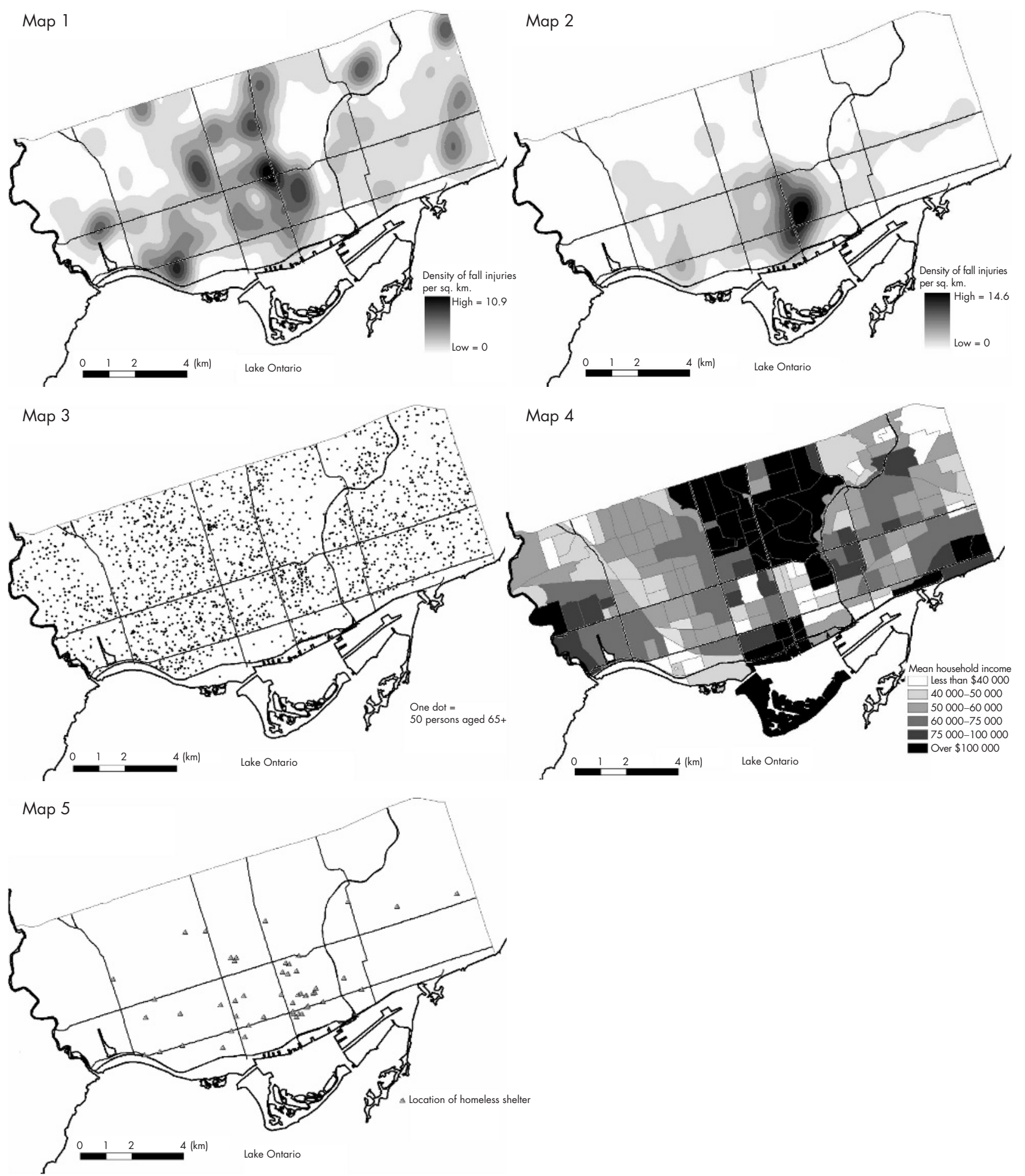

Figure 1 Map 1: density of fall injuries for patients aged > 65 years; Map 2: density of fall injuries for patients aged 19-64 years; Map 3: density of population aged >65 years; Map 4: Mean household income by census tract; Map 5: Homeless shelters.

\section{LIMITATIONS OF THE GEOMATICS APPROACH}

The quality of the data is paramount in any population-based approach that is dependent on data. As many communitybased interventions require information at the community-level to design, implement and evaluate prevention strategies, the robustness of the data at the level of interest determines the ability of geomatics to inform the process of prevention. Privacy issues and laws in many countries limit the ability to collect and use data in ways that can deal with community-level issues. Agencies that collect these data may be unable or unwilling to release detailed data that are meaningful to practitioners. Aggregating data across time or space overcomes this limitation in many jurisdictions.

The collection or aggregation of data by geographical locations such as census tracts or ZIP codes may not necessarily have relevance to injury events. For example, when studying 
traffic injuries, major roads often make up the boundaries of the areas and retail activity tends to be clustered along these arterial roads. Therefore, this needs to be taken into consideration in the development of GIS and in spatial analysis.

When undertaking geographical analysis, it is also important to note the issue of ecological fallacy. The ecological fallacy may be present whenever assumptions that are based solely on group characteristics are made about people in a group. For instance, when associating particular socioeconomic characteristics with injury risk factors (for instance, low income), it cannot be assumed that people living in high-risk areas are directly represented by the general characteristics of those areas. Also, the characteristics of a particular area can change on the basis of scale, a phenomenon known as the modifiable areal unit problem, as a result of variance in an area. ${ }^{23}$ Bias in ecological studies can include the modifiable areal unit problem, as well as not accounting for long-term exposure in many public health studies. ${ }^{53}$ Again, given the sudden nature of injury, this last point is less of a concern. Taylor et al ${ }^{54}$ provide an excellent example for the modifiable areal unit problem, studying socioeconomic segregation between schools in the UK.

Although GIS can show associations of community-based data with injury data, it is important to understand that in and of itself, GIS cannot infer causality. However, GIS can inform the interpretation of causal relationships in many ways. GIS can provide a rational basis for causality; it can assess dose-response effects and changes over time and risk exposure, and can also be used as an analytical tool before and after interventions. It can also be used in a predictive capacity to help understand how the present state might change with interventions directed at changes in community-based risk factors.

\section{CONCLUSION}

Globally, the use of GIS as a tool in disease surveillance, the planning and evaluation of health promotion and prevention programs has been recognized, with increasing usage and application, although many areas, such as injury prevention, could benefit from more intensive uptake of the science. The inherent advantages of GIS include the ability to display spatial data in a way that can be easily interpreted and analyzed, the combination of multiple data sources to find spatial patterns and for prediction, and the ability to share these data with multiple users in ways that are efficient and have an effect on policy and planning. Developments such as interactive, public web-based applications allow the opportunity for the translation and use of these spatial data by community stakeholders at multiple levels.

Geomatics supports novel approaches in the public health discipline that hold great promise to combat disease and the burden of injury. It provides a framework with considerable opportunities for those in this discipline to come together to discuss the devastating problems that affect our communities around the world.

\footnotetext{
Authors' affiliations

M D Cusimano, R H Glazier, Department of Surgery, University of Toronto, Toronto, Ontario, Canada M D Cusimano, M Chipman, R H Glazier, Department of Public Health Sciences, University of Toronto, Toronto, Ontario, Canada R H Glazier, Department of Family Medicine, University of Toronto, Toronto, Ontario, Canada

C Rinner, Department of Geography, University of Toronto, Toronto, Ontario, Canada

R H Glazier, Center for Inner City Health, St Michael's Hospital, Toronto, Ontario, Canada

M D Cusimano, S P Marshall, Injury Prevention Research Office, St Michael's Hospital, Toronto, Ontario, Canada

Competing interests: None declared.
}

\section{REFERENCES}

1 GEOIDE. GEOIDE Vision: Working document of the Research Management Committee. Québec: Geomatics for Informed Decisions (GEOIDE) Network of Centers of Excellence, 2003.

2 World Health Organization. Geographical Information Systems (GIS). Wkly Epidemiol Rec 1999:74:281-8.

3 DeMers MN. In: Fundamentals of geographic information systems, 3rd edn. Hoboken, NJ: John Wiley, 2005:4-5.

4 Kistemann T, Dangendorf F, Schweikart J. New perspectives on the use of Geographic Information Systems (GIS) in environmental health sciences. Int J Hyg Environ Health 2002;205:169-81.

5 Briggs $D$, Elliott $P$. The use of geographical information systems in studies on environment and health. World Health Stat Q 1995;48:85-94.

6 Reissman DB, Staley F, Curtis GB, et al. Use of geographic information system technology to aid health department decision making about childhood lead poisoning prevention activities. Environ Health Perspect 2001;109:89-94.

7 Glass GE, Schwartz BS, Morgan JM III, et al. Environmental risk factors for Lyme disease identified with geographic information systems. Am J Public Health 1995;85:944-8.

8 Monmonier M. Geographic brushing: enhancing exploratory analysis of the scatterplot matrix. Geog Anal 1989;21:81-4.

9 DiBiase D. Visualization in the earth sciences, Earth and Mineral Sciences. Vol 59. Bulletin of the College of Earth and Mineral Sciences, Penn State University, 1990:13-18.

10 Beck LG, Rodrigues MH, Dister SW, et al. Remote sensing as a landscape epidemiologic tool to identify villages at high risk for malaria transmission. epidemiologic tool to identify villages at
Am J Trop Med Hyg 1994;51:271-80.

11 Parchman ML, Ferrer RL, Blanchard KS. Geography and geographic information systems in family medicine research. Family Med 2002;34:132-7.

12 Barnes S, Peck A. Mapping the future of health care: GIS application in health care analysis. Geogr Inf Syst 1994;4:31-3.

13 Kerani RP, Handcock MS, Handsfield H, et al. Comparative geographic concentrations of 4 sexually transmitted infections. Am J Public Health 2005:95:324-9.

14 Ali M, Emch M, Donnay J. Spatial filtering using a raster geographic information system: methods for scaling health and environmental data. Health Place 2002;8:85-92.

15 Peled R, Reuveni H, Pliskin JS, et al. Defining localities of inadequate treatment for childhood asthma: a GIS approach. Int J Health Geogr 2006;5:3.

16 Moonan PK, Bayona M, Quitugua TN, et al. Using GIS technology to identify areas of tuberculosis transmission and incidence. Int J Health Geogr 2004;23:3.

17 Bullen N, Moon G, Jones K. Defining localities for health planning: a GIS approach. Soc Sci Med 1996:42:801-16.

18 Elliott SJ, Eyles J, DeLuca P. Mapping health in the Great Lakes areas of concern: a user-friendly tool for policy and decision makers. Environ Health Perspect $2001 ; 109$ (Suppl. 6):S817-26.

19 Aultman-Hall L, Hall FL. Ottawa-Carleton commuter cyclist on-and off-road incident rates. Accid Anal Prev 1997;30:29-43.

20 Aultman-Hall L, Kaltenecker MG. Toronto bicycle commuter safety rates. Accid Anal Prev 1999;31:675-86.

21 Buckeridge DL, Purdon L. Health Data Mapping in Southeast Toronto: A Collaborative Project. Geographic Information Systems in Public Health, Third National Conference. Toronto, Ontario, 1998:15-22.

22 Buckeridge DL, Mason R, Robertson A, et al. Making health data maps: a case study of a community/university research collaboration. Soc Sci Med 2002;55:1189-206.

23 Glazier RH, Creatore MI, Gozdyra P, et al. Geographic methods for understanding and responding to disparities in mammography use in Toronto, Canada. J Gen Intern Med 2004; 19:952-61.

24 Grigg M, Alfred B, Keller C, et al. Implementation of an Internet-based Geographic Information System: the Florida experience. J Public Health Manag Pract 2006;12:139-45.

25 Ratcliffe JH. Crime mapping and the training needs of law enforcement. Eur J Criminal Policy Res 2004; 10:65-83.

26 The Toronto Star Homicides in the GTA. Web-based map, 2006. http:// www.thestar.com/static/googlemaps/starmaps. html?xml=homicides. $x m$ (accessed 6 Oct 2006).

27 Gruenewald PJ, Freisthler B, Remer L, et al. Ecological models of alcohol outlets and violent assaults: crime potentials and geospatial analysis. Addiction 2006;101:666-77.

28 World Health Organization. Facts about injuries, WHO Injuries and Violence Prevention Office.http://www.who.int/violence_injury_prevention/resources/ publications/en/injury_factsheet.pdf (accessed 5 Oct 2006).

29 Centers for Disease Control and Prevention. 10 Leading causes of death by age group - 2002, National Center for Injury Prevention and Control.ftp:// ftp.cdc.gov/pub/ncipc/10lc-2002/pdf/10lc-2002.pdf (accessed 6 Oct 2006)

30 Jacquez GM, Greiling DA, Kaufmann AM. Design and implementation of a Space-Time Intelligence System for disease surveillance. J Geogr Syst 2005;7:7-23.

31 D'Cunha C Chief Medical Officer of Health Report. Injury: Predictable and Preventable. Toronto, Ontario: Queen's Printer for Ontario, 2002.

32 Stevenson M, McClure R. Use of ecological study designs for injury prevention. Inj Prev 2005; 11:2-4.

33 Kivell P, Mason K. Trauma systems and major injury centers for the 21 st century: an option. Health Place 1999;5:99-110.

34 Braddock M, Lapidus G, Cromley E, et al. Using a geographic information system to understand child pedestrian injury. Am J Public Health 1994;84:1158-61. 
35 Lightstone AS, Dhillon, PK, Peek-Asa C, et al. A geographic analysis of motor vehicle collisions with child pedestrians in Long Beach, California comparing intersection and midblock incident locations. Inj Prev 2001;7:155-60.

36 LaScala EA, Gerber D, Gruenewald PJ. Demographic and environmental correlates of pedestrian injury collisions: a spatial analysis. Accid Anal Prev 2000;32:651-8.

$37 \mathrm{Ng} \mathrm{K}$, Hung W, Wong W. An algorithm for assessing the risk of traffic accident. $J$ Safety Res 2002;33:387-410.

38 Pierce J, Ray LU, Woods S, et al. Creating and using a geographic information system for motor vehicle-related injury surveillance in San Diego County. Top Emerg Med 1999:21:26-31.

39 Midford R, Stockwell TR, Daly A, et al. Alcohol consumption and injury in Western Australia: a spatial correlation analysis using geographic information systems. Aust N Z J Public Health 1998;22:80-85.

40 Zavoski RW, Lapidus GD, Lerer TJ, et al. Evaluating the impact of a street barrier on urban crime. Inj Prev, 1999;5, 65-68.

41 Earnst JS. Mapping child maltreatment: looking at neighborhoods in a suburban county. Child Welfare 2000;79:555-72.

42 Latkin C, Glass GE, Duncan T. Using geographic information systems to assess spatial patterns of drug use, selection bias and attrition among a sample of injection drug users. Drug Alcohol Depend 1998;50:167-75.

43 Pickett W, Garner MJ, Boyce WF, et al. Gradients in risk for youth injury associated with multiple risk behaviours: a study of 11,329 Canadian children. Soc Sci Med 2002:55:1055-68.

44 Macpherson A, Schull M, Manuel D, et al. Injuries in Ontario, Institute for Clinical Evaluative Sciences, September 2005.http://www.ices.on.ca/ webpage. $\mathrm{cfm}$ ? site id $=1$ \&org id $=67$ \&morg_id $=0 \&$ gsec_id $=0$ \&item_id $=3053 \&$ type $=$ atlas (accessed 6 Oct 2006).

45 Theseira M. Using Internet GIS technology for sharing health and health related data for the West Midlands Region. Health Place 2002;8:37-46.

46 Nedovic-Budic Z, Pinto J. Interorganizational GIS: issues and prospects. Ann Reg Sci 1999;33:183-95.

47 Robinson TP. Spatial statistics and geographical information systems in epidemiology and health. Adv Parasitol 2000:47:81-128.

48 Richards TB, Croner CM, Novick LF. Geographic information systems (GIS) for state and local public health practitioners, Part 2. J Public Health Manag Pract 1999:5: 1-6.

49 Higgs $\mathbf{G}$. Sharing environmental data across organizational boundaries: lessons from the rural Wales terrestrial database project. Ann Reg Sci 1999;33:233-49.

50 Kingston R, Carver S, Evans S, et al. Web-based public participation geographical information systems: an aid to local environmental decisionmaking. Comput Environ Urban Syst 2000;24:109-25.

51 Mowat DL, Gosselin P, Bedard Y, et al. Improving health surveillance in Canada - what are the needs? National Health Surveillance Infostructure, 2000.

52 Higgs G, Gould M. Is there a role for GIS in the "new NHS"? Health Place 2001;7:247-59.

53 Wakefield J. A critique of statistical aspects of ecological studies in spatial epidemiology Environ Soc Stat 2004;1 1:31-54

54 Taylor C, Gorard S, Fitz J. The modifiable areal unit problem: segregation between schools and levels of analysis. Int J Social Res Methodol 2003;6:41-60. 